\title{
Cell-Derived Microparticles in Patients with Type 2 Diabetes Mellitus: a Systematic Review and Meta-Analysis
}

\author{
Sheyu Lia Jia Wei Chenghui Zhang ${ }^{\mathrm{a}, \mathrm{d}}$ Xiaodan Li ${ }^{\mathrm{b}} \quad$ Wentong Meng ${ }^{\mathrm{c}}$ \\ Xianming Moc Qianying Zhang ${ }^{a}$ Qilin Liu ${ }^{a}$ Kaiyun Ren ${ }^{a}$ Rong Duad \\ Haoming Tian ${ }^{\mathrm{a}}$ Jianwei Li ${ }^{\mathrm{a}}$ \\ aDepartment of Endocrinology and Metabolism and bDepartment of Gastroenterology, 'Laboratory of \\ Stem Cell Biology, West China Hospital, Sichuan University, Chengdu, dDepartment of Endocrinology \\ and Metabolism, West China Hospital Chengban Branch, Sichuan University, Chengdu, China
}

\section{Key Words}

Type 2 diabetes mellitus - Microparticles - Biomarker - Platelet-derived microparticle • Endothelium-derived microparticle

\begin{abstract}
Background/Aims: The aim of this study was to assess the association between circulating cell-derived microparticles (MPs) and type 2 diabetes mellitus (T2DM). Methods: A literature search was performed systematically in PubMed and Embase to identify available case-control or cross-sectional studies that compared different types of cell-derived MPs in patients with T2DM and non-diabetic controls. Pooled standardized mean differences (SMDs) of each MP type were pooled using meta-analysis. Results: Forty-eight studies involving 2,460 patients with T2DM and 1,880 non-diabetic controls were included for systematic review and 34 of which were included for quantitative study by meta-analysis. In the overall analysis, the levels of circulating total MPs (TMPs), platelet-derived MPs (PMPs), monocyte-derived MPs (MMPs) and endothelium-derived MPs (EMPs) were significantly higher in T2DM patients than those in controls (TMPs: SMD, 0.64; 95\%CI, 0.12 1.15; P=0.02; PMPs: SMD, 1.19; 95\%CI, 0.88 1.50; $\mathrm{P}<0.00001$; MMPs: SMD, 0.92; 95\%CI, 0.66 1.17; P <0.00001; EMPs: SMD, 0.73; 95\%CI, $0.50 \sim 0.96 ; \mathrm{P}<0.00001)$. Meanwhile, no significant difference was shown in leukocyte-derived MPs (LMPs) level between diabetic and non-diabetic groups (SMD, 0.37; 95\%CI, $-0.15 \sim 0.89$; $\mathrm{P}=0.17$ ). Conclusions: The counts of TMPs, PMPs, MMPs and EMPs elevated in patients with T2DM. And cell-derived MPs may play a role in the pathogenesis of T2DM.
\end{abstract}




\section{Cellular Physiology Cell Physiol Biochem 2016;39:2439-2450 \begin{tabular}{l|l|l} 
and Biochemistry Published online: November 11, 2016 & $\begin{array}{l}\text { C } 2016 \text { The Author(s). Published by S. Karger AG, Basel } \\
\text { www.karger.com/cpb }\end{array}$
\end{tabular} \\ Li et al.: Cell-Derived Microparticles in T2DM}

\section{Introduction}

Type 2 diabetes mellitus (T2DM) is one of the most common chronic diseases with substantial burden worldwide [1]. It induces organ damage and cell apoptosis associating with energy deficiency, oxidative stress and advanced glycation end products $[2,3]$. Microparticles (MPs), small membrane vesicles measuring 0.1 1.0 $\mu \mathrm{m}$ in diameter, are produced during the apoptosis and stimulation of various cell types, such as platelets, leukocytes, monocytes, erythrocytes, and endothelial cells [4-7]. Being overlooked for years, MPs are now considered as extracellular organelles with a variety of functions involving coagulation, inflammation, vascular function and transfer of biologic information [8-11].

Even though accumulating evidence indicated the quantity changes of different MPs in type 2 diabetic patients, as well as the association between MPs and diabetic vasculopathies and neurological complications, it is still uncertain whether the MPs counts could serve as biomarkers of T2DM. In this study, we systemically collected and analyzed the available literatures to evaluate the quantity and phenotype of MPs in different population.

\section{Materials and Methods}

\section{Literature-search strategy}

The literature search was performed by two independent investigators (S.L. and J.W.) through October 2015 without restriction to regions or publication types. The sources were the electronic databases of PubMed and Embase. According to the search strategy, medical subject heading (MeSH) terms and keywords like "diabetes", "microparticle", "microparticles" and "cell-derived microparticle" were applied.

\section{Inclusion and exclusion criteria}

A study with the following features was considered eligible: (1) designed as a case-control or crosssectional study, (2) including patients with type 2 diabetes mellitus and controls without T2DM, (3) compared counts of any interested MPs between case and control group. The interested MPs were as following: the total microparticles (TMPs), platelet-derived microparticles (PMPs), leukocyte-derived microparticles (LMPs), monocyte-derived microparticles (MMPs) and endothelium-derived microparticles (EMPs). The results were further limited to human studies published in English or Chinese. Conference abstracts were excluded due to insufficient information. When multiple reports based on the same population were published, only reports with larger sample size were analyzed.

\section{Data extraction}

All relevant data from the included studies were extracted independently by two of the authors (S.L. and J.W.). We extracted the following data from each study: the first author's name, publication year, country, sample size, participant characteristics (age, gender, BMI, HbA1c, fasting glucose) and interested outcomes as described above. Disagreement was settled by consensus between the two reviewers.

\section{Quality assessment}

The methodological quality of included studies was assessed by the Newcastle-Ottawa Quality assessment scale (NOS), which consists of three factors: participant selection, comparability of the study groups, and exposure. A score of 0-9 was allocated to each study.

\section{Statistical analysis}

All statistical analyses were performed using Review Manager 5.3 (Cochrane Collaboration, Oxford, UK) and STATA version 12.0 (STATA, College Station, TX, USA). The standardized mean differences (SMDs) and their 95\% confidence intervals (CIs) were used to compare continuous variables. Random-effect models were used in all pooled analyses in the study due to the significant clinical heterogeneity of the included studies. Subgroup analyses were conducted according to the co-morbidities of participants. Sensitivity assays and meta-regression analyses were performed when studies showed high heterogeneity. Publication bias was evaluated using the funnel plot, Egger's test and Begg's test. 
Li et al.: Cell-Derived Microparticles in T2DM

\section{Results}

\section{Literature selection}

As shown in Fig. 1, 713 records were identified, and 48 studies involving 2,460 patients with type 2 diabetes and 1,880 non-diabetic controls were included in the systematic review [12-59]. Among them, data from 34 reports were meta-analyzed since the others [12, 14, $20,23,24,29,30,33,34,37,39,40,46,58]$ did not provide available data for pooling the interested outcomes. Among the reports for qualitative analyses only, results of TMPs [26], PMPs [12, 20, 28-30, 33, 34, 39, 40, 58] and MMPs [26, 29, 32, 40] were controversial, while the results of LMPs [39, 58] and EMPs [14, 20, 23, 24, 26, 29, 37, 39, 40, 58] were consistent with each other.

The characteristics of included studies were shown in Table 1 and Table 2. Meanwhile, we briefly summarized the methodologies for MP detection and the special detection

Table 1. Characteristics of included studies. ACS, acute coronary syndrome; AMI, acute myocardial infarction; AS, atherosclerotic disease; CAD, coronary artery disease; DVC, diabetic vascular complications; ED, erectile dysfunction; ELISA, enzyme-linked immunosorbent assay; EMPs, endothelium-derived microparticles; HC, healthy controls; HP, hypertension; HPL, hyperlipidemia; LMPs, leukocyte-derived microparticles; MMPs, monocyte-derived microparticles; PMPs, platelet-derived microparticles; TMPs, the total microparticles; T2DM, type 2 diabetes mellitus; XaCT, factor Xa based clotting assay

\begin{tabular}{|c|c|c|c|c|c|c|c|c|c|}
\hline \multirow{2}{*}{ Study ID } & \multirow{2}{*}{ Country } & \multirow{2}{*}{ Patient } & \multirow{2}{*}{ Control } & \multirow{2}{*}{ Detection method } & \multicolumn{5}{|c|}{ Outcomes of study } \\
\hline & & & & & PMPS & EMPS & & MMPs & TMPS \\
\hline Nomura, S. 1995 [22] & Japan & T2DM & $\mathrm{HC}$ & Flow cytometry & $\sqrt{ }$ & & & & \\
\hline Watala, C. 1998 [25] & Poland & T2DM & $\mathrm{HC}$ & Flow cytometry & $\sqrt{ }$ & & & & \\
\hline Omoto, S. 1999 [19] & Japan & T2DM & $\mathrm{HC}$ & Flow cytometry & j & & & & \\
\hline Nomura, S. 2000 [35] & Japan & T2DM & $\mathrm{HC}$ & Flow cytometry & s & & & & \\
\hline Sabatier, F. 2002 [32] & France & T2DM & $\mathrm{HC}$ & Flow cytometry & $\sqrt{ }$ & $\sqrt{ }$ & $\sqrt{ }$ & $\sqrt{ }$ & $\sqrt{ }$ \\
\hline Diamant, M. 2002 [26] & Netherlands & T2DM & $\mathrm{HC}$ & Flow cytometry & $\sqrt{ }$ & $\sqrt{ }$ & & $\sqrt{ }$ & $\sqrt{ }$ \\
\hline Nomura, S. $2002[44]$ & Japan & T2DM \& HP & Non-DM \& HP & Flow cytometry & $\sqrt{ }$ & & & $\sqrt{ }$ & \\
\hline Nomura, S. $2003[55]$ & Japan & T2DM \& HPL & $\mathrm{HC}$ & Flow cytometry & $\sqrt{ }$ & & & $\sqrt{ }$ & \\
\hline Shouzu, A. 2004 [47] & Japan & T2DM & $\mathrm{HC}$ & Flow cytometry & $\sqrt{ }$ & & & $\sqrt{ }$ & \\
\hline Morel, 0.2004 [21] & France & T2DM \& AMI & Non-DM \& AMI & Prothrombinase assay & $\sqrt{ }$ & $\sqrt{ }$ & $\sqrt{ }$ & & \\
\hline Morel, 0. 2004 [21] & France & T2DM & $\mathrm{HC}$ & Prothrombinase assay & j & $\sqrt{ }$ & & & \\
\hline Nomura, S. 2004 [45] & Japan & T2DM \& HP & Non-DM \& HP & Flow cytometry & & & & $\sqrt{ }$ & \\
\hline Nomura, S. 2004a [53] & Japan & T2DM \& HP \& HPL & Non-DM \& HP \& HPL & Flow cytometry & $\sqrt{ }$ & $\sqrt{ }$ & & & \\
\hline Nomura, S. 2004a [53] & Japan & T2DM \& HP & $\mathrm{HC}$ & Flow cytometry & $\sqrt{ }$ & $\sqrt{ }$ & & & \\
\hline Nomura, S. 2004b [49] & Japan & T2DM \& HPL & Non-DM \& HPL & Flow cytometry & $\sqrt{ }$ & & & $\sqrt{ }$ & \\
\hline Nomura, S. 2004c [16] & Japan & T2DM & $\mathrm{HC}$ & Flow cytometry & $\sqrt{ }$ & $\sqrt{ }$ & & & \\
\hline Sommeijer, D.W. 2005 [46] & Holland & T2DM & $\mathrm{HC}$ & Flow cytometry & $\sqrt{ }$ & $\sqrt{ }$ & & $\sqrt{ }$ & \\
\hline Koga, H. 2005 [17] & Japan & T2DM \& CAD/non-CAD & Non-DM \& non-CAD & Flow cytometry & & $\sqrt{ }$ & & & \\
\hline Tan, K.T. 2005 [12] & UK & T2DM \& AS/non-AS & $\mathrm{HC}$ & Flow cytometry & $\sqrt{ }$ & & & & \\
\hline Nomura, S. 2005 [43] & Japan & T2DM & $\mathrm{HC}$ & Flow cytometry & $\sqrt{ }$ & & & & \\
\hline Nomura, S. 2005 a [50] & Japan & T2DM \& HP & Non-DM \& HP & Flow cytometry & $\sqrt{ }$ & & & $\sqrt{ }$ & \\
\hline Nomura, S. 2005 b [51] & Japan & T2DM \& HP & Non-DM \& HP & Flow cytometry & & $\sqrt{ }$ & & $\sqrt{ }$ & \\
\hline Nomura, S. 2006 [52] & Japan & T2DM \& HP & Non-DM \& HP & Flow cytometry & & & & $\sqrt{ }$ & \\
\hline Koga, H. 2006 [36] & Japan & T2DM \& non-CAD & Non-DM \& non-CAD & Flow cytometry & $\sqrt{ }$ & & & & \\
\hline Esposito, K. 2007 [20] & Italy & T2DM \& ED & Non-DM \& non-ED & Flow cytometry & $\sqrt{ }$ & $\sqrt{ }$ & & & \\
\hline Nomura, S. 2007 [57] & Japan & T2DM & $\mathrm{HC}$ & Flow cytometry & $\sqrt{ }$ & $\sqrt{ }$ & & $\sqrt{ }$ & \\
\hline Nomura, S. $2007[57]$ & Japan & T2DM \& HP & Non-DM \& HP & Flow cytometry & $\sqrt{ }$ & $\sqrt{ }$ & & $\sqrt{ }$ & \\
\hline Tushuizen, M.E. 2007 [31] & Netherlands & T2DM & $\mathrm{HC}$ & Flow cytometry & & $\sqrt{ }$ & & & \\
\hline Inami, N. 2008 [59] & Japan & T2DM \& HPL & Non-DM \& HPL & ELISA kit & $\sqrt{ }$ & & & & \\
\hline Raturi, A. 2008 [34] & USA & T2DM & $\mathrm{HC}$ & Flow cytometry & $\sqrt{ }$ & & & & \\
\hline Esposito, K. 2008 [24] & Italy & T2DM \& ED & Non-DM \& ED & Flow cytometry & & $\sqrt{ }$ & & & \\
\hline Razmara M. 2008 [33] & Sweden & T2DM & $\mathrm{HC}$ & Flow cytometry & $\sqrt{ }$ & & & & \\
\hline Shimazu, T. 2009 [48] & Japan & T2DM & Non-DM \& HP & ELISA kit & j & & & & \\
\hline Van Dreden, P. 2009 [30] & Australia & T2DM & $\mathrm{HC}$ & $\mathrm{XaCT}$ assay & $\sqrt{ }$ & & & & \\
\hline Nomura, S. 2009 [13] & Japan & $\mathrm{T} 2 \mathrm{DM} \& \mathrm{HP}$ & Non-DM \& HP & Flow cytometry & j & $\sqrt{ }$ & & $\sqrt{ }$ & \\
\hline Nomura, S. 2009a [56] & Japan & T2DM \& HPL & $\mathrm{HC}$ & ELISA kit & $\sqrt{ }$ & & & & \\
\hline Nomura, S. 2009b [54] & Japan & T2DM \& HPL & Non-DM \& HPL & Flow cytometry & & $\sqrt{ }$ & & & \\
\hline Tramontano A.F. 2010 [14] & USA & T2DM \& CAD & Non-DM \& CAD & Flow cytometry & & $\sqrt{ }$ & & & \\
\hline Curtis, A.M. 2010 [29] & Ireland & T2DM & $\mathrm{HC}$ & Flow cytometry & $\sqrt{ }$ & $\sqrt{ }$ & & $\sqrt{ }$ & \\
\hline Feng, B. 2010 [39] & China & T2DM & $\mathrm{HC}$ & Flow cytometry & $\sqrt{ }$ & $\sqrt{ }$ & $\sqrt{ }$ & & \\
\hline Xiang, H. 2010 [27] & China & T2DM & $\mathrm{HC}$ & flow cytometry & & $\sqrt{ }$ & & & \\
\hline Xiang, H. $2010[27]$ & China & T2DM \& HP & Non-DM \& HP & Flow cytometry & & $\sqrt{ }$ & & & \\
\hline Tripodi. A. 2011 [15] & Italy & T2DM & $\mathrm{HC}$ & Flow cytometry & s & & & & $\sqrt{ }$ \\
\hline Tsimerman, G. 2011 [18] & Israel & T2DM \& DVC & $\mathrm{HC}$ & Flow cytometry & $\sqrt{ }$ & $\sqrt{ }$ & & & $\sqrt{ }$ \\
\hline Lanuti, P. 2012 [37] & Italy & T2DM & $\mathrm{HC}$ & Flow cytometry & & $\sqrt{ }$ & & & \\
\hline Chen, Y. 2012 [58] & China & T2DM \& HP/Non-HP & $\mathrm{HC}$ & Flow cytometry & $\sqrt{ }$ & $\sqrt{ }$ & $\sqrt{ }$ & & \\
\hline Jansen, F. 2013 [42] & Germany & T2DM \& CAD & Non-DM \& CAD & Flow cytometry & & $\sqrt{ }$ & & & \\
\hline Alkhatatbeh, M.J. 2013 [40] & Australia & T2DM \& Obese & Non-DM \& Obese & Flow cytometry & $\sqrt{ }$ & $\sqrt{ }$ & & $\sqrt{ }$ & \\
\hline Lumsden, N.G. 2013 [28] & Australia & T2DM \& ACS & $\mathrm{HC}$ & Flow cytometry & j & $\sqrt{ }$ & & & \\
\hline Kurtzman, N. 2013 [38] & USA & T2DM \& AS & $\mathrm{HC}$ & Flow cytometry & v & $\sqrt{ }$ & $\sqrt{ }$ & & \\
\hline Zhang, X. 2014 [41] & UK & T2DM & $\mathrm{HC}$ & Flow cytometry & $\sqrt{ }$ & & $\sqrt{ }$ & $\sqrt{ }$ & \\
\hline Berezin. A.E. 2015 [23] & Ukraine & T2DM & $\mathrm{HC}$ & Flow cytometry & & $\sqrt{ }$ & & & \\
\hline
\end{tabular}


Table 2. Clinical characteristics of participants in the included studies. Data are presented as mean (type 2 diabetic patients/ non-diabetic controls). BMI, body mass index; HbA1c, glycosylated hemoglobin A1c; NA, data not available

\begin{tabular}{|c|c|c|c|c|c|c|}
\hline Study ID & Number & Female proportion (\%) & Age (years) & BMI $\left(\mathrm{kg} / \mathrm{m}^{2}\right)$ & Glucose (mmol/L) & HbA1c (\%) \\
\hline Nomura, S. 1995 [22] & $18 / 18$ & $44.40 \% / 38.90 \%$ & $55 / 42$ & $\mathrm{NA} / \mathrm{NA}$ & $\mathrm{NA} / \mathrm{NA}$ & $\mathrm{NA} / \mathrm{NA}$ \\
\hline Watala, C. 1998 [25] & $33 / 37$ & $36.36 \% / 24.32 \%$ & $48 / 41$ & $27.8 / 21.8$ & $9.7 / 5.33$ & $8.74 / 5.47$ \\
\hline Omoto, S. 1999 [19] & $48 / 30$ & $\mathrm{NA} / \mathrm{NA}$ & $\mathrm{NA} / \mathrm{NA}$ & $\mathrm{NA} / \mathrm{NA}$ & NA/NA & NA/NA \\
\hline Nomura, S. 2000 [35] & $37 / 20$ & $59.50 \% / 35 \%$ & $56 / 48$ & $25.4 / 23.3$ & $\mathrm{NA} / \mathrm{NA}$ & $7.8 / 4.8$ \\
\hline Sabatier, F. 2002 [32] & $52 / 47$ & $50 \% / 61.70 \%$ & $57 / 44$ & $28.8 / 22.0$ & $8.9 / 4.0$ & NA/NA \\
\hline Diamant, M. 2002 [26] & $16 / 18$ & $25 \% / 22.20 \%$ & $54 / 55$ & $25.8 / 24.3$ & $7.7 / 5.4$ & $5.8 / 4.9$ \\
\hline Nomura, S. 2002 [44] & $23 / 25$ & $\mathrm{NA} / \mathrm{NA}$ & $\mathrm{NA} / \mathrm{NA}$ & $\mathrm{NA} / \mathrm{NA}$ & $\mathrm{NA} / \mathrm{NA}$ & NA/NA \\
\hline Nomura, S. 2003 [55] & $23 / 20$ & $45 \% / 47.80 \%$ & $61 / 57$ & $27.1 / 22.4$ & $\mathrm{NA} / \mathrm{NA}$ & 7.8/NA \\
\hline Shouzu, A. 2004 [47] & $73 / 50$ & $58.90 \% / 42 \%$ & $54 / 51$ & $22.9 / 22.4$ & $\mathrm{NA} / \mathrm{NA}$ & $7.9 / 4.9$ \\
\hline Morel, 0. 2004 [21] & $19 / 33$ & $5.26 \% / 15.15 \%$ & $67 / 59$ & $27.8 / 27.9$ & $9.95 / 5.66$ & NA/NA \\
\hline Morel, 0. 2004 [21] & $22 / 50$ & $\mathrm{NA} / \mathrm{NA}$ & $63 / 42$ & $\mathrm{NA} / \mathrm{NA}$ & NA/NA & NA/NA \\
\hline Nomura, S. 2004 [45] & $30 / 18$ & $63.30 \% / 44.40 \%$ & $67 / 64$ & $24.6 / 23.9$ & $\mathrm{NA} / \mathrm{NA}$ & 9.4/NA \\
\hline Nomura, S. 2004a [53] & $16 / 11$ & $56.25 \% / 45.45 \%$ & $68 / 65$ & $25.3 / 23.8$ & $\mathrm{NA} / \mathrm{NA}$ & $8.4 / 4.9$ \\
\hline Nomura, S. 2004a [53] & $14 / 25$ & $71.43 \% / 36 \%$ & $66 / 56$ & $24.5 / 23.7$ & $\mathrm{NA} / \mathrm{NA}$ & $8.9 / 4.6$ \\
\hline Nomura, S. 2004b [49] & $27 / 26$ & $40.74 \% / 42.31 \%$ & $62 / 59$ & $27.9 / 25.8$ & $\mathrm{NA} / \mathrm{NA}$ & $\mathrm{NA} / \mathrm{NA}$ \\
\hline Nomura, S. 2004c [16] & $65 / 40$ & $58.50 \% / 37.50 \%$ & $55 / 50$ & $22.9 / 22.7$ & $\mathrm{NA} / \mathrm{NA}$ & $7.8 / 4.7$ \\
\hline Sommeijer, D.W. 2005 [46] & $48 / 10$ & $\mathrm{NA} / \mathrm{NA}$ & $59 / \mathrm{NA}$ & $29 / \mathrm{NA}$ & $\mathrm{NA} / \mathrm{NA}$ & $\mathrm{NA} / \mathrm{NA}$ \\
\hline Koga, H. 2005 [17] & $232 / 102$ & $36.60 \% / 45.10 \%$ & $66.6 / 66.1$ & $24.0 / 24.4$ & $7.0 / 5.3$ & $6.7 / 5.2$ \\
\hline Tan, K.T. 2005 [12] & $18 / 21 / 21$ & $38.9 \% / 38.1 \% / 61.90 \%$ & $71 / 68 / 67$ & $25.1 / 29.5 / \mathrm{NA}$ & $\mathrm{NA} / \mathrm{NA} / \mathrm{NA}$ & NA/NA/NA \\
\hline Nomura, S. 2005 [43] & $53 / 30$ & $54.70 \% / 26.70 \%$ & $55 / 52$ & $24.3 / 22.2$ & $\mathrm{NA} / \mathrm{NA}$ & $7.9 / 4.7$ \\
\hline Nomura, S. 2005a [50] & $32 / 11$ & $65.60 \% / 72.70 \%$ & $66 / 62$ & $23.9 / 23.6$ & $\mathrm{NA} / \mathrm{NA}$ & $9.6 / 5.2$ \\
\hline Nomura, S. 2005b [51] & $28 / 10$ & $57.10 \% / 60 \%$ & $65 / 60$ & $23.7 / 23.8$ & NA/NA & $9.5 / 5.4$ \\
\hline Nomura, S. 2006 [52] & $28 / 25$ & $64.30 \% / 64 \%$ & $67 / 61$ & $24.4 / 23.9$ & $\mathrm{NA} / \mathrm{NA}$ & $9.8 / 5.4$ \\
\hline Koga, H. 2006 [36] & $105 / 92$ & $35.20 \% / 43.50 \%$ & $62.4 / 64.4$ & $23.9 / 23.7$ & $7.6 / 5.3$ & $7.0 / 5.2$ \\
\hline Esposito, K. 2007 [20] & $30 / 20$ & $0 \% / 0 \%$ & $57.2 / 53.9$ & $29.6 / 27.4$ & $9.4 / 5.8$ & $8.2 / 5.2$ \\
\hline Nomura, S. 2007 [57] & $15 / 28$ & $33.30 \% / 35.70 \%$ & $56 / 56$ & $23.5 / 23.2$ & NA/NA & $7.3 / 4.3$ \\
\hline Nomura, S. 2007 [57] & $40 / 33$ & $55 \% / 60.60 \%$ & $66 / 61$ & $23.9 / 23.7$ & NA/NA & $8.6 / 5.1$ \\
\hline Tushuizen, M.E. 2007 [31] & $15 / 12$ & $0 \% / 0 \%$ & $55 / \mathrm{NA}$ & $\mathrm{NA} / \mathrm{NA}$ & NA/NA & $7.1 / \mathrm{NA}$ \\
\hline Inami, N. 2008 [59] & $52 / 65$ & $53.80 \% / 64.60 \%$ & $62 / 65$ & $26.5 / 25.5$ & $\mathrm{NA} / \mathrm{NA}$ & $\mathrm{NA} / \mathrm{NA}$ \\
\hline Raturi, A. 2008 [34] & $10 / 10$ & $\mathrm{NA} / \mathrm{NA}$ & NA/NA & $\mathrm{NA} / \mathrm{NA}$ & $\mathrm{NA} / \mathrm{NA}$ & $\mathrm{NA} / \mathrm{NA}$ \\
\hline Esposito, K. 2008 [24] & $30 / 24$ & $0 \% / 0 \%$ & $56.3 / 57.2$ & $29.1 / 28.6$ & $8.3 / 5.4$ & $5.9 / 8.0$ \\
\hline Razmara, M. 2008 [33] & $12 / 12$ & $66.70 \% / 66.70 \%$ & $58 / 59$ & $26.1 / 25.0$ & $12.0 / 4.6$ & $6.2 / 4.6$ \\
\hline Shimazu, T. 2009 [48] & $30 / 38$ & $46.70 \% / 44.70 \%$ & $63 / 61$ & $27.4 / 25.1$ & NA/NA & $7.1 / 4.8$ \\
\hline Van Dreden, P. 2009 [30] & $12 / 30$ & NA/ $53.3 \%$ & $42 / 42$ & $\mathrm{NA} / \mathrm{NA}$ & NA/NA & NA/NA \\
\hline Nomura, S. 2009 [13] & $176 / 183$ & $58.50 \% / 55.20 \%$ & $65 / 62$ & $24.4 / 23.9$ & NA/NA & $8.2 / 5.3$ \\
\hline Nomura, S. 2009a [56] & $191 / 30$ & $47.12 \% / 43.33 \%$ & $65 / 56$ & $27.3 / 25.4$ & $\mathrm{NA} / \mathrm{NA}$ & $7.0 / 4.9$ \\
\hline Nomura, S. 2009b [54] & $76 / 50$ & $46 \% / 48 \%$ & $66 / 55$ & $27.4 / 25.9$ & NA/NA & $7.2 / 4.8$ \\
\hline Tramontano, A.F. 2010 [14] & $20 / 20$ & $50 \% / 66.70 \%$ & $63.7 / 70.8$ & $33.5 / 27.5$ & $7.9 / 5.9$ & $\mathrm{NA} / \mathrm{NA}$ \\
\hline Curtis, A.M. 2010 [29] & $11 / 22 / 18$ & $36 \% / 19 \% / 39 \%$ & $51 / 64 / 57$ & $\mathrm{NA} / \mathrm{NA} / \mathrm{NA}$ & $\mathrm{NA} / \mathrm{NA} / \mathrm{NA}$ & $7.2 / 7.1 / 5.3$ \\
\hline Feng, B. 2010 [39] & $63 / 29$ & $52.40 \% / 52 \%$ & $61.7 / 58.9$ & $24.0 / 23.6$ & $\mathrm{NA} / \mathrm{NA}$ & $9.3 / 4.9$ \\
\hline Xiang, H. 2010 [27] & $48 / 50$ & $58.30 \% / 66.00 \%$ & $57.1 / 56.5$ & $21.9 / 21.8$ & $9.0 / 5.8$ & NA/NA \\
\hline Xiang, H. 2010 [27] & $50 / 46$ & $64 \% / 65.20 \%$ & $55.7 / 56.2$ & $22.5 / 23.7$ & $8.3 / 5.4$ & $\mathrm{NA} / \mathrm{NA}$ \\
\hline Tripodi, A. 2011 [15] & $60 / 60$ & $36.70 \% / 36.70 \%$ & $64 / 59$ & NA/NA & $7.7 / \mathrm{NA}$ & $6.8 / \mathrm{NA}$ \\
\hline Tsimerman, G. 2011 [18] & $123 / 41$ & $35 \% / 63 \%$ & $62 / 55$ & $\mathrm{NA} / \mathrm{NA}$ & $\mathrm{NA} / \mathrm{NA}$ & NA/NA \\
\hline Lanuti, P. 2012 [37] & $20 / 14$ & $25 \% / 50 \%$ & $65.2 / \mathrm{NA}$ & $28.6 / \mathrm{NA}$ & $7.15 / \mathrm{NA}$ & $6.5 / \mathrm{NA}$ \\
\hline Chen, Y. 2012 [58] & $39 / 24 / 20$ & $64.1 \% / 33.3 \% / 65 \%$ & $64.9 / 56.4 / 57.9$ & $24.3 / 23.5 / 22.7$ & $\mathrm{NA} / \mathrm{NA} / \mathrm{NA}$ & $9.4 / 9.3 / 5.0$ \\
\hline Jansen, F. 2013 [42] & $50 / 126$ & $38 \% / 27 \%$ & $68.0 / 66.2$ & $29.4 / 27.6$ & $9.4 / 6.0$ & $\mathrm{NA} / \mathrm{NA}$ \\
\hline Alkhatatbeh, M.J. 2013 [40] & $33 / 33$ & $45.50 \% / 45.50 \%$ & $57.1 / 56.2$ & $40.0 / 33.6$ & $\mathrm{NA} / \mathrm{NA}$ & $7.7 / \mathrm{NA}$ \\
\hline Lumsden, N.G. 2013 [28] & $15 / 16$ & $6.70 \% / 18.75 \%$ & $57.6 / 58.3$ & $33.2 / 23.4$ & $8.66 / 5.10$ & $\mathrm{NA} / \mathrm{NA}$ \\
\hline Kurtzman, N. 2013 [38] & $48 / 48$ & $39.58 \% / 62.50 \%$ & $66 / 59$ & $31.0 / 24.0$ & $\mathrm{NA} / \mathrm{NA}$ & $7.0 / 5.6$ \\
\hline Zhang, X. 2014 [41] & $10 / 20$ & $20 \% / 35 \%$ & $62 / 51$ & $31.0 / 31.0$ & $\mathrm{NA} / \mathrm{NA}$ & NA/NA \\
\hline Berezin, A.E. 2015 [23] & $54 / 35$ & $37 \% / 34.30 \%$ & $48.5 / 46.12$ & $28.5 / 21.5$ & $5.54 / 4.52$ & $7.3 / 4.75$ \\
\hline
\end{tabular}

markers of the included studies, for online supplementary material, see www.karger.com/ doi/10.1159/000452512, Table S1 and Table S2.

\section{Quality assessment of included studies}

The median score of NOS in each included study was 4 (ranged from 2 to 7). None of these retrospective studies mentioned the non-response rate. Only three studies $[24,28,31]$ provided information about the blinding method of measurement. Ten studies described the matching information $[12,15,20,24,26,28,31-33,40]$, and the matching strategies were various. The details of quality assessment of each included study were shown in the supplementary material- Table S3.

\section{Meta-analysis}

Three studies compared the count of TMPs in 139 T2DM patients and 122 non-diabetic controls. The pooled TMP count in T2DM patients was significantly higher than that in the controls (SMD, 0.64; 95\%CI, 0.12 1.15; P=0.02; Fig. 2A). Twenty-four studies investigated 
Fig. 1. Flow diagram of studies identified, included and excluded.

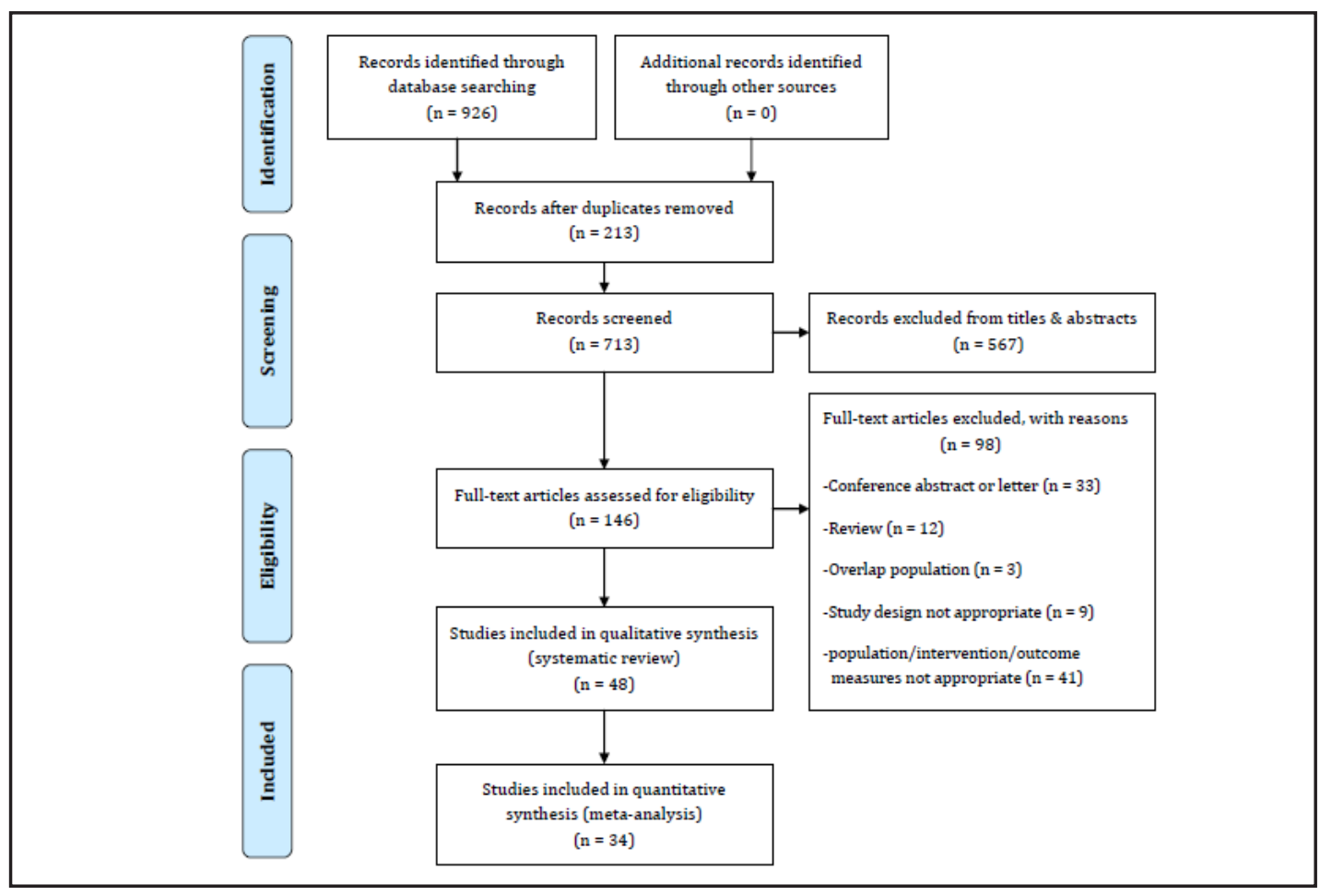

the count of PMPs in 1,255 T2DM patients and 1,051 non-diabetic controls. The pooled circulating PMP count in T2DM patients was significantly higher than that in the controls (SMD, 1.19; 95\%CI, 0.88 1.50; P <0.00001; Fig. 2B).

Eleven studies reported the concentration of MMPs in 496 T2DM patients and 446 nondiabetic controls. The pooled plasma MMP count in T2DM patients was significantly higher than that in the controls (SMD, 0.92; 95\%CI, 0.66 1.17; P <0.00001; Fig. 2C). Fifteen studies detected the count of EMPs in 995 T2DM patients and 929 non-diabetic controls. The pooled EMP concentration in T2DM patients was also significantly higher than that in the controls (SMD, 0.73; 95\%CI, 0.50 0.96; P <0.00001; Fig. 2E). Four studies compared LMP counts in 129 patients with T2DM and 148 non-diabetic controls. However, the pooled data displayed no significant difference between the two study groups (SMD, 0.37; 95\%CI, $-0.15 \sim 0.89$; $\mathrm{P}=0.17$; Fig. 2D).

\section{Subgroup analysis and meta-regression}

Subgroup analyses based on the characteristics of participants were introduced to explore the potential source of heterogeneity. We divided studies concerning TMPs, PMPs, MMPs, LMPs and EMPs into three subgroups: unspecified T2DM patients versus healthy controls, T2DM patients with co-morbidities versus healthy controls and T2DM patients with co-morbidities versus non-diabetic patients with co-morbidities. As shown in the supplementary material Table S4 and Fig. S1, all pooled results among subgroups were consistent with the overall analysis.

In order to further understand the roles of activated/apoptotic MPs in T2DM, we conducted the analyses on the subgroup of studies which detected annexin $V$ positive or negative EMPs and PMPs. The result of EMPs was similar to the original analysis, whereas the annexin $\mathrm{V}^{+} \mathrm{PMP}$ counts showed no significant difference between T2DM and non-diabetic controls (see supplementary material Fig. S2).

Univariable meta-regression analyses on each kind of MPs were performed with the covariates including publication year, sample size, female proportion, and the mean age, mean $\mathrm{BMI}$ and mean HbA1c in T2DM group. The meta-regressions by the mean age, mean BMI and 


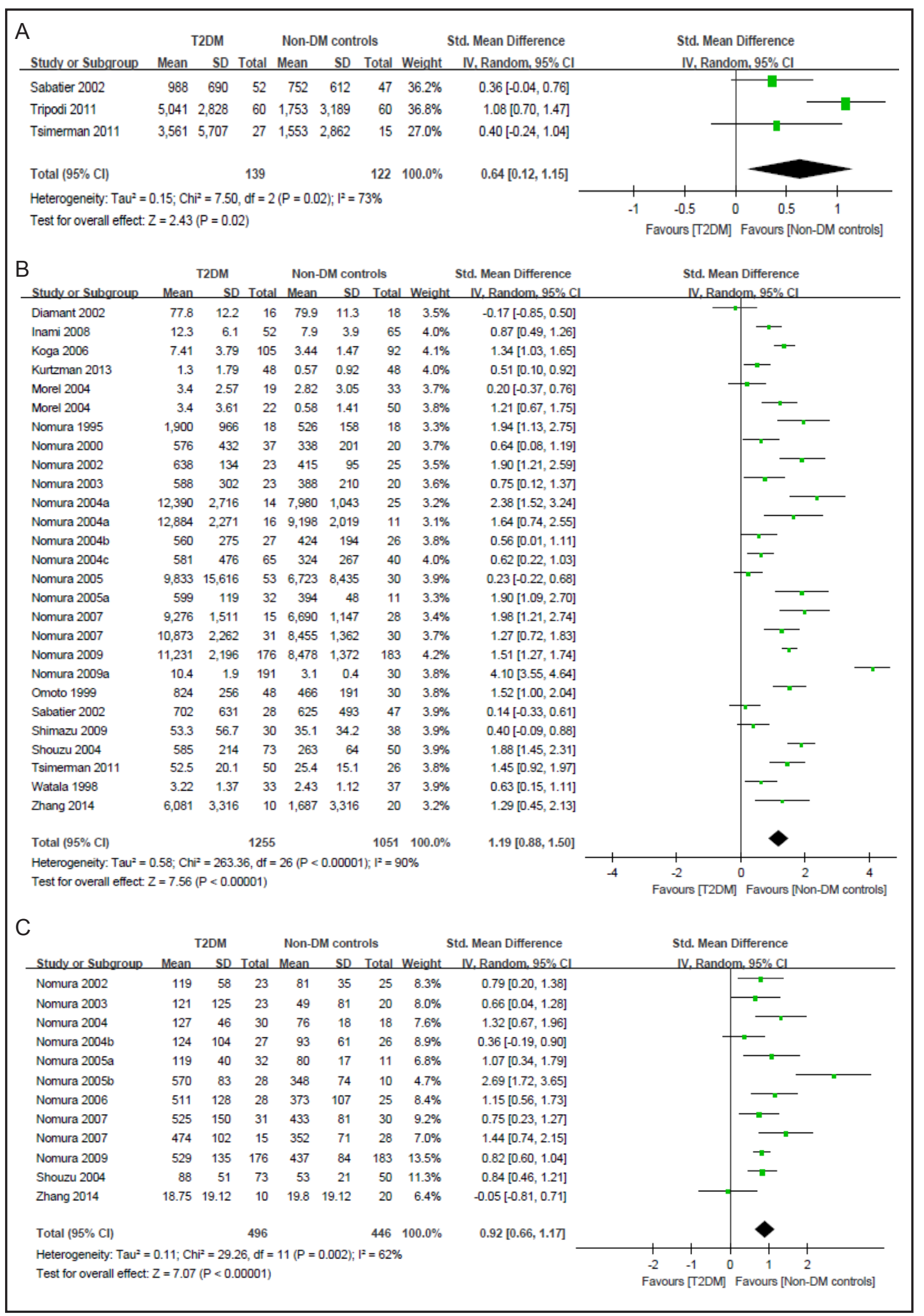

mean HbA1c on TMPs and mean HbA1c on LMPs were dropped due to the insufficient data. However, no significant association between interested MPs and candidate covariates was found (see supplementary material Table S5 and Fig. S3). 


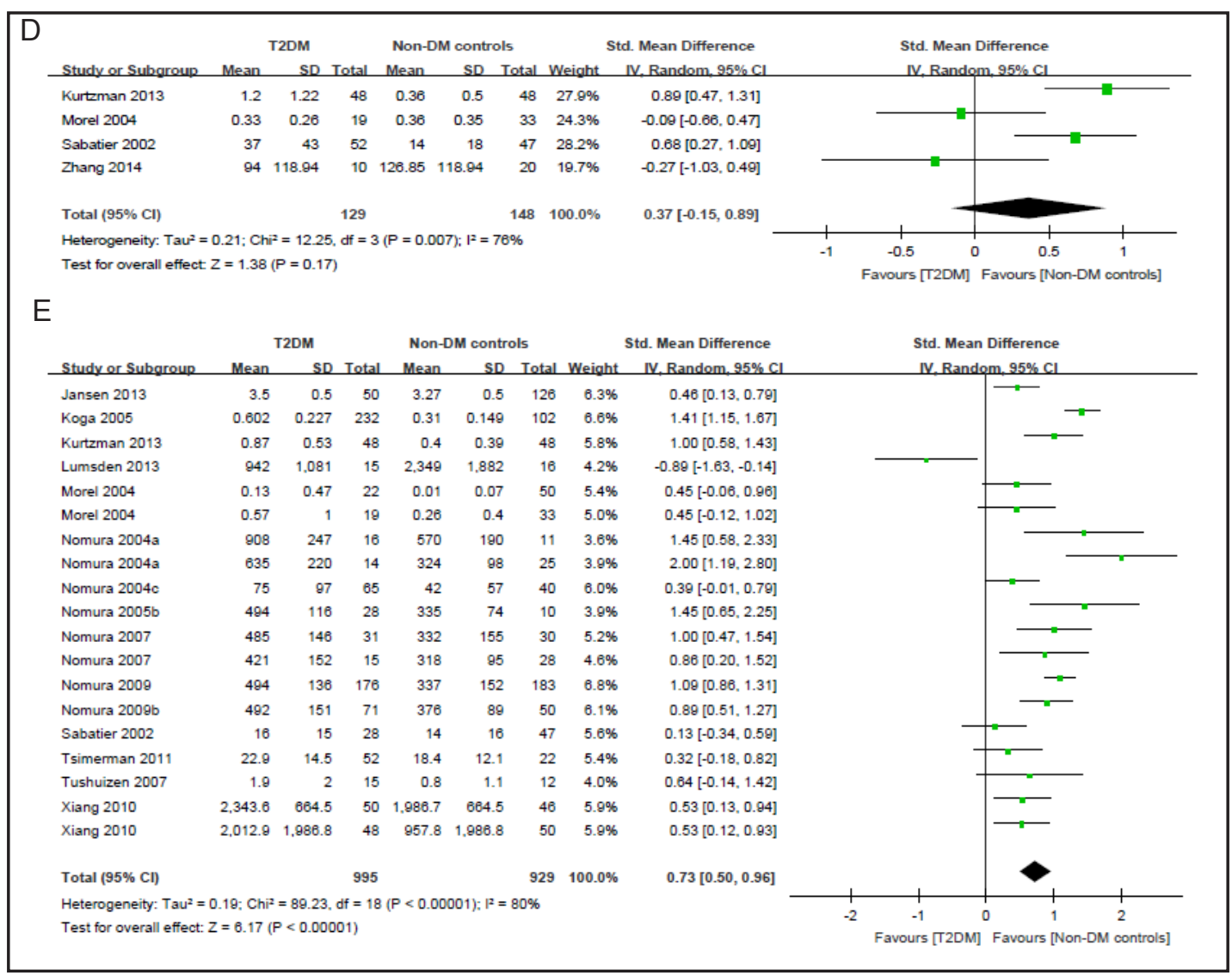

Fig. 2. Forest plots and meta-analyses of each microparticle type for the type 2 diabetic patients compared with non-diabetic controls. (A. Forest plot and meta-analysis of TMPs; B. Forest plot and meta-analysis of PMPs; C. Forest plot and meta-analysis of MMPs; D. Forest plot and meta-analysis of LMPs; E. Forest plot and meta-analysis of EMPs). CI, confidence interval; EMPs, endothelium-derived microparticles; IV, inverse variance method; LMPs, leukocyte-derived microparticles; MMPs, monocyte-derived microparticles; NonDM controls, non-diabetic controls; PMPs, platelet-derived microparticles; SD, standard deviation; Std. mean difference, standardized mean difference; TMPs, the total microparticles; T2DM, type 2 diabetes mellitus.

\section{Sensitivity analysis and publication bias assessment}

Sensitivity analyses were conducted to assess the robustness of our findings. In the 24 studies concerning PMPs, excluding one study at a time, the pooled SMDs were not substantially influenced by any of the individual study (see supplementary material Fig. S4A). Sensitivity analyses for reports concerning MMPs and EMPs confirmed the stability of results as well (see supplementary material Fig. S4B, S4C). We did not conduct the sensitivity analyses on studies with regard to TMPs or LMPs since too few literatures were included.

The funnel plots, Egger's tests and Begg's tests of the studies included in this metaanalysis that compared the counts of TMPs, PMPs, MMPs, LMPs and EMPs between T2DM patients and non-diabetic controls, respectively are showed in the supplementary material Fig. S5. Studies lie with an asymmetrical distribution around the vertical, indicating the potential publication bias may exist.

\section{Discussion}

Regardless of types of controls and co-morbidities, our systematic review indicated the counts of TMPs, PMPs, MMPs and EMPs, but not LMPs, significantly elevated in patients 


\section{Cellular Physiology Cell Physiol Biochem 2016;39:2439-2450

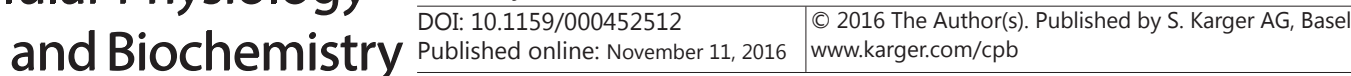 \\ Li et al.: Cell-Derived Microparticles in T2DM}

with T2DM. This is the first systematic review evaluating the various MPs in T2DM patients comparing with those in non-diabetic controls. Although potential heterogeneity between studies exists, our results were robust in the subgroup analyses and sensitivity analyses, indicating the elevation of these MPs counts in T2DM was significant.

In T2DM patients, exposure to persistent hyperglycemia leads to organ damage associated with oxidative-stress-induced apoptosis $[2,60]$, which participates in the release of various cell-derived MPs. Annexin V, a typical marker of apoptosis, was used as a marker of plasma apoptotic MPs in most of the studies on MPs. Three studies in the current analysis indicated that TMPs, labeled with annexin V, were higher in T2DM patients compared with non-diabetic controls. Although the mechanisms are not completely elucidated, the increased level of circulating MPs in T2DM could be at least partially related to hyperglycemia-associated cell apoptosis and associated dysfunction in coagulation, inflammation, autoimmunity and endothelium $[9,61,62]$. Meanwhile, the relationship between the elevated MP count and the pathogenesis of T2DM could not be denied.

PMPs constituted the majority of total plasma MPs, served as the typical marker of platelet activation [63]. Our analyses suggested that annexin V negative PMPs, but not annexin $V$ positive PMPs, were significantly elevated in T2DM patients. Since only participants without thrombotic disease were enrolled in the included studies, it indicated that diabetes might be associated with the impaired platelet function and excessive activation of platelets, which had been confirmed by previous studies [19, 22, 64]. Furthermore, some investigators found PMPs were also elevated in patients with atherosclerosis or other diabetic macro- and micro-vascular complications $[16,18,22,38,65,66]$, which suggested that elevated PMPs might be associated with hyperglycemia-induced organ damage in T2DM patients.

MPs derived from activated or apoptotic endothelial cells varied in immunophenotype [67-69]. Generally, CD31 and CD105 were used as markers of apoptotic EMPs, while CD62E was used as the marker of activated EMPs [67]. Subgroup analyses for CD molecular markers were not performed because of insufficient data, and the subgroup analysis based on annexin V positive or negative EMPs showed no significant difference compared with original analysis. However, instead of activated EMPs, apoptotic EMPs counts were significantly elevated in T2DM patients according to the original reports [14, 24, 39]. Moreover, the increased ratio of $\mathrm{CD} \mathrm{E}^{+} / \mathrm{CD} 31^{+} \mathrm{EMP}$ counts in T2DM patients also reflected an increased apoptotic activity in diabetes $[14,23,24]$.

Our study also has several limitations. Firstly, the methodology for detecting MPs varies among the included studies. A standardized method with stable results and convenient procedure is needed before using MP as a biomarker of diabetes. Secondly, the strength of the pooled results was restricted by the low reporting quality of included studies. Thirdly, a potential publication bias was detected by both funnel graph and Egger's test, which might result in an overestimation of the association. Nevertheless, the robustness of our results was confirmed by sensitivity analyses. Fourthly, most of the included studies were crosssectional, and the causation between MPs changes and T2DM could hardly be drawn. Some longitudinal cohort studies are required to demonstrate how these MPs participate in the pathogenesis of T2DM and its associated organ damage.

\section{Conclusions}

In summary, counts of TMP, PMP, MMP and EMP in T2DM patients were significantly higher than those in non-diabetic controls. It indicated MPs may play a role in the pathogenesis of T2DM or its complications, which was associated with coagulation, immune and endothelial dysfunction. A standard, convenient and stable methodology for detecting each MP is essential in the future investigations before they can be used as conventional biomarkers of T2DM and associated organ damages. And subsets of each MP in longitudinal observation are still required to further explore the pathogenesis of diabetes and its complications. 


\section{Cellular Physiology Cell Physiol Biochem 2016;39:2439-2450 and Biochemistry Published online: November 11, 2016 \begin{tabular}{l|l} 
DOI: 10.1159/000452512 2016 The Author(s). Published by S. Karger AG, Basel \\
www.karger.com/cpb
\end{tabular} \\ Li et al.: Cell-Derived Microparticles in T2DM}

\section{Abbreviations}

BMI (body mass index); CD (clusters of differentiation); CI (confidence interval); EMPs (endothelium-derived microparticles); HbA1c (glycosylated hemoglobin A1c); LMPs (leukocyte-derived microparticles); MeSH (medical subject heading term); MMPs (monocyte-derived microparticles); MPs (cell-derived microparticles); NOS (NewcastleOttawa Quality assessment scale); PMPs (platelet-derived microparticles); TMPs (the total microparticles); SMD (standard mean difference); T2DM (type 2 diabetes mellitus).

\section{Acknowledgements}

The study was supported by grants from the National Natural Science Foundation of China (Grant No. 81400811 and 21534008), National Basic Research Program of China (2015CB942800), and the Scientific Research Project of Health and Family Planning Commission of Sichuan Province (Grant No. 130029 and 150149).

\section{Disclosure Statement}

The authors report no conflict of interest.

\section{References}

1 Rahelic D: $7^{\text {th }}$ Edition of IDF DIABETES ATLAS--CALL FOR IMMEDIATE ACTION. Lijec Vjesn 2016;138:5758.

2 Allen DA, Yaqoob MM, Harwood SM: Mechanisms of high glucose-induced apoptosis and its relationship to diabetic complications. J Nutr Biochem 2005;16:705-713.

3 Min C, Kang E, Yu SH, Shinn SH, Kim YS: Advanced glycation end products induce apoptosis and procoagulant activity in cultured human umbilical vein endothelial cells. Diabetes Res Clin Pract 1999;46:197-202.

4 Nomura S, Ozaki Y, Ikeda Y: Function and role of microparticles in various clinical settings. Thromb Res 2008;123:8-23.

$5 \quad$ Nomura S, Shimizu M: Clinical significance of procoagulant microparticles. J Intensive Care 2015;3:2.

6 Angelillo-Scherrer A: Leukocyte-derived microparticles in vascular homeostasis. Circ Res 2012;110:356369.

7 Vajen T, Mause SF, Koenen RR: Microvesicles from platelets: novel drivers of vascular inflammation. Thromb Haemost 2015;114:228-236.

8 Freyssinet JM: Cellular microparticles: what are they bad or good for? J Thromb Haemost 2003;1:16551662.

9 Berckmans RJ, Nieuwland R, Boing AN, Romijn FP, Hack CE, Sturk A: Cell-derived microparticles circulate in healthy humans and support low grade thrombin generation. Thromb Haemost 2001;85:639-646.

10 Li H, Han L, Yang Z, Huang W, Zhang X, Gu Y, Li Y, Liu X, Zhou L, Hu J, Yu M, Yang J, Li Y, Zheng Y, Guo J, Han J, Li L: Differential Proteomic Analysis of Syncytiotrophoblast Extracellular Vesicles from Early-Onset Severe Preeclampsia, using 8-Plex iTRAQ Labeling Coupled with 2D Nano LC-MS/MS. Cell Physiol Biochem 2015;36:1116-1130.

11 Diamant M, Tushuizen ME, Sturk A, Nieuwland R: Cellular microparticles: new players in the field of vascular disease? Eur J Clin Invest 2004;34:392-401.

12 Tan KT, Tayebjee MH, Lim HS, Lip GY: Clinically apparent atherosclerotic disease in diabetes is associated with an increase in platelet microparticle levels. Diabet Med 2005;22:1657-1662. 


\section{Cellular Physiology Cell Physiol Biochem 2016;39:2439-2450 \begin{tabular}{l|l|l} 
and Biochemistry & $\begin{array}{l}\text { DOI: 10.1159/000452512 } \\
\text { Published online: November 11, } 2016\end{array}$ & $\begin{array}{l}\text { C } 2016 \text { The Author(s). Published by S. Karger AG, Basel } \\
\text { www.karger.com/cpb }\end{array}$
\end{tabular} \\ Li et al.: Cell-Derived Microparticles in T2DM}

13 Nomura S, Inami N, Shouzu A, Urase F, Maeda Y: Correlation and association between plasma platelet-, monocyte- and endothelial cell-derived microparticles in hypertensive patients with type 2 diabetes mellitus. Platelets 2009;20:406-414.

14 Tramontano AF, Lyubarova R, Tsiakos J, Palaia T, Deleon JR, Ragolia L: Circulating endothelial microparticles in diabetes mellitus. Mediators Inflamm 2010;2010:250476.

15 Tripodi A, Branchi A, Chantarangkul V, Clerici M, Merati G, Artoni A, Mannucci PM: Hypercoagulability in patients with type 2 diabetes mellitus detected by a thrombin generation assay. J Thromb Thrombolysis 2011;31:165-172.

16 Nomura S, Shouzu A, Omoto S, Nishikawa M, Iwasaka T, Fukuhara S: Activated platelet and oxidized LDL induce endothelial membrane vesiculation: Clinical significance of endothelial cell-derived microparticles in patients with type 2 diabetes. Clin Appl Thromb Hemost 2004;10:205-215.

17 Koga H, Sugiyama S, Kugiyama K, Watanabe K, Fukushima H, Tanaka T, Sakamoto T, Yoshimura M, Jinnouchi H, Ogawa H: Elevated levels of VE-cadherin-positive endothelial microparticles in patients with type 2 diabetes mellitus and coronary artery disease. J Am Coll Cardiol 2005;45:1622-1630.

18 Tsimerman G, Roguin A, Bachar A, Melamed E, Brenner B, Aharon A: Involvement of microparticles in diabetic vascular complications. Thromb Haemost 2011;106:310-321.

19 Omoto S, Nomura S, Shouzu A, Hayakawa T, Shimizu H, Miyake Y, Yonemoto T, Nishikawa M, Fukuhara S, Inada M: Significance of platelet-derived microparticles and activated platelets in diabetic nephropathy. Nephron 1999;81:271-277.

20 Esposito K, Ciotola M, Giugliano F, Schisano B, Improta L, Improta MR, Beneduce F, Rispoli M, De Sio M, Giugliano D: Endothelial microparticles correlate with erectile dysfunction in diabetic men. Int J Impot Res 2007;19:161-166.

21 Morel O, Hugel B, Jesel L, Lanza F, Douchet MP, Zupan M, Chauvin M, Cazenave JP, Freyssinet JM, Tori F: Sustained elevated amounts of circulating procoagulant membrane microparticles and soluble GPV after acute myocardial infarction in diabetes mellitus. Thromb Haemost 2004;91:345-353.

22 Nomura S, Suzuki M, Katsura K, Xie GL, Miyazaki Y, Miyake T, Kido H, Kagawa H, Fukuhara S: Plateletderived microparticles may influence the development of atherosclerosis in diabetes mellitus. Atherosclerosis 1995;116:235-240.

23 Berezin AE, Kremzer AA, Samura TA, Berezina TA, Kruzliak P: Impaired immune phenotype of circulating endothelial-derived microparticles in patients with metabolic syndrome and diabetes mellitus. J Endocrinol Invest 2015;38:865-874.

24 Esposito K, Ciotola M, Giugliano F, Sardelli L, Giugliano F, Maiorino MI, Beneduce F, De Sio M, Giugliano D: Phenotypic assessment of endothelial microparticles in diabetic and nondiabetic men with erectile dysfunction. J Sex Med 2008;5:1436-1442.

25 Watala C, Boncer M, Golanski J, Koziolkiewcz W, Trojanowski Z, Walkowiak B: Platelet membrane lipid fluidity and intraplatelet calcium mobilization in type 2 diabetes mellitus. Eur J Haematol 1998;61:319326.

26 Diamant M, Nieuwland R, Pablo RF, Sturk A, Smit JW, Radder JK: Elevated numbers of tissue-factor exposing microparticles correlate with components of the metabolic syndrome in uncomplicated type 2 diabetes mellitus. Circulation 2002;106:2442-2447.

27 Xiang H, Huang R, Zhou YL: [Influences of hypertension and diabetes on arterial compliances and endothelial microparticle level]. Nan Fang Yi Ke Da Xue Xue Bao 2010;30:2387-2389.

28 Lumsden NG, Andrews KL, Bobadilla M, Moore XL, Sampson AK, Shaw JA, Mizrahi J, Kaye DM, Dart AM, Chin-Dusting JP: Endothelial dysfunction in patients with type 2 diabetes post acute coronary syndrome. Diab Vasc Dis Res 2013;10:368-374.

29 Curtis AM, Zhang L, Medenilla E, Gui M, Wilkinson PF, Hu E, Giri J, Doraiswamy V, Gunda S, Burgert ME, Moore JS, Edelberg JM, Mohler ER, 3rd: Relationship of microparticles to progenitor cells as a measure of vascular health in a diabetic population. Cytometry B Clin Cytom 2010;78:329-337.

30 Van Dreden P, Rousseau A, Fontaine S, Woodhams BJ, Exner T: Clinical evaluation of a new functional test for detection of plasma procoagulant phospholipids. Blood Coagul Fibrinolysis 2009;20:494-502.

31 Tushuizen ME, Nieuwland R, Rustemeijer C, Hensgens BE, Sturk A, Heine RJ, Diamant M: Elevated endothelial microparticles following consecutive meals are associated with vascular endothelial dysfunction in type 2 diabetes. Diabetes Care 2007;30:728-730. 


\section{Cellular Physiology Cell Physiol Biochem 2016;39:2439-2450 \begin{tabular}{l|l|l} 
DOI: 10.1159/000452512 & $\begin{array}{l}\text { C 2016 The Author(s). Published by S. Karger AG, Basel } \\
\text { www.karger.com/cpb }\end{array}$
\end{tabular} \\ Li et al.: Cell-Derived Microparticles in T2DM}

32 Sabatier F, Darmon P, Hugel B, Combes V, Sanmarco M, Velut JG, Arnoux D, Charpiot P, Freyssinet JM, Oliver C, Sampol J, Dignat-George F: Type 1 and type 2 diabetic patients display different patterns of cellular microparticles. Diabetes 2002;51:2840-2845.

33 Razmara M, Hjemdahl P, Ostenson CG, Li N: Platelet hyperprocoagulant activity in Type 2 diabetes mellitus: Attenuation by glycoprotein IIb/IIIa inhibition. J Thromb Haemost 2008;6:2186-2192.

34 Raturi A, Miersch S, Hudson JW, Mutus B: Platelet microparticle-associated protein disulfide isomerase promotes platelet aggregation and inactivates insulin. Biochim Biophys Acta 2008;1778:2790-2796.

35 Nomura S, Shouzu A, Omoto S, Nishikawa M, Fukuhara S: Significance of chemokines and activated platelets in patients with diabetes. Clin Exp Immunol 2000;121:437-443.

36 Koga H, Sugiyama S, Kugiyama K, Fukushima H, Watanabe K, Sakamoto T, Yoshimura M, Jinnouchi H, Ogawa $\mathrm{H}$ : Elevated levels of remnant lipoproteins are associated with plasma platelet microparticles in patients with type-2 diabetes mellitus without obstructive coronary artery disease. Eur Heart J 2006;27:817-823.

37 Lanuti P, Santilli F, Marchisio M, Pierdomenico L, Vitacolonna E, Santavenere E, Iacone A, Davi G, Romano M, Miscia S: A novel flow cytometric approach to distinguish circulating endothelial cells from endothelial microparticles: Relevance for the evaluation of endothelial dysfunction. J Immunol Methods 2012;380:1622.

38 Kurtzman N, Zhang L, French B, Jonas R, Bantly A, Rogers WT, Moore JS, Rickels MR, Mohler ER: Personalized cytomic assessment of vascular health: Evaluation of the vascular health profile in diabetes mellitus. Cytometry B Clin Cytom 2013;84:255-266.

39 Feng B, Chen Y, Luo Y, Chen M, Li X, Ni Y: Circulating level of microparticles and their correlation with arterial elasticity and endothelium-dependent dilation in patients with type 2 diabetes mellitus. Atherosclerosis 2010;208:264-269.

40 Alkhatatbeh MJ, Enjeti AK, Acharya S, Thorne RF, Lincz LF: The origin of circulating CD36 in type 2 diabetes. Nutr Diabetes 2013;3:e59.

41 Zhang X, McGeoch SC, Johnstone AM, Holtrop G, Sneddon AA, MacRury SM, Megson IL, Pearson DWM, Abraham P, De Roos B, Lobley GE, O'Kennedy N: Platelet-derived microparticle count and surface molecule expression differ between subjects with and without type 2 diabetes, independently of obesity status. J Thromb Thrombolysis 2014;37:455-463.

42 Jansen F, Yang X, Hoelscher M, Cattelan A, Schmitz T, Proebsting S, Wenzel D, Vosen S, Franklin BS, Fleischmann BK, Nickenig G, Werner N: Endothelial microparticle-mediated transfer of microRNA-126 promotes vascular endothelial cell repair via spred1 and is abrogated in glucose-damaged endothelial microparticles. Circulation 2013;128:2026-2038.

43 Nomura S, Shouzu A, Omoto S, Nishikawa M, Iwasaka T: 5-HT2A receptor antagonist increases circulating adiponectin in patients with type 2 diabetes. Blood Coagul Fibrinolysis 2005;16:423-428.

44 Nomura S, Kanazawa S, Fukuhara S: Effects of efonidipine on platelet and monocyte activation markers in hypertensive patients with and without type 2 diabetes mellitus. J Hum Hypertens 2002;16:539-547.

45 Nomura S, Shouzu A, Omoto S, Nishikawa M, Iwasaka T: Effects of Losartan and Simvastatin on MonocyteDerived Microparticles in Hypertensive Patients with and Without Type 2 Diabetes Mellitus. Clin Appl Thromb Hemost 2004;10:133-141.

46 Sommeijer DW, Joop K, Leyte A, Reitsma PH, ten Cate H: Pravastatin reduces fibrinogen receptor gpIIIa on platelet-derived microparticles in patients with type 2 diabetes. J Thromb Haemost 2005;3:1168-1171.

47 Shouzu A, Nomura S, Omoto S, Hayakawa T, Nishikawa M, Iwasaka T: Effect of Ticlopidine on Monocytederived Microparticles and Activated Platelet Markers in Diabetes Mellitus. Clin Appl Thromb Hemost 2004;10:167-173.

48 Shimazu T, Inami N, Satoh D, Kajiura T, Yamada K, Iwasaka T, Nomura S: Effect of acarbose on plateletderived microparticles, soluble selectins, and adiponectin in diabetic patients. J Thromb Thrombolysis 2009;28:429-435.

49 Nomura S, Takahashi N, Inami N, Kajiura T, Yamada K, Nakamori H, Tsuda N: Probucol and ticlopidine: Effect on platelet and monocyte activation markers in hyperlipidemic patients with and without type 2 diabetes. Atherosclerosis 2004;174:329-335.

50 Nomura S, Shouzu A, Omoto S, Nishikawa M, Iwasaka T: Long-term treatment with nifedipine modulates procoagulant marker and C-C chemokine in hypertensive patients with type 2 diabetes mellitus. Thromb Res 2005;115:277-285. 


\section{Cellular Physiology Cell Physiol Biochem 2016;39:2439-2450

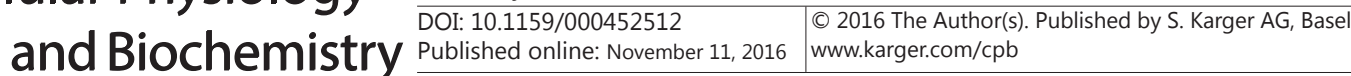 \\ Li et al.: Cell-Derived Microparticles in T2DM}

51 Nomura S, Shouzu A, Omoto S, Nishikawa M, Iwasaka T: Benidipine improves oxidized LDL-dependent monocyte and endothelial dysfunction in hypertensive patients with type 2 diabetes mellitus. J Hum Hypertens 2005;19:551-557.

52 Nomura S, Shouzu A, Omoto S, Nishikawa M, Fukuhara S, Iwasaka T: Effect of valsartan on monocyte/ endothelial cell activation markers and adiponectin in hypertensive patients with type 2 diabetes mellitus. Thromb Res 2006;117:385-392.

53 Nomura S, Shouzu A, Omoto S, Nishikawa M, Fukuhara S, Iwasaka T: Losartan and simvastatin inhibit platelet activation in hypertensive patients. J Thromb Thrombolysis 2004;18:177-185.

54 Nomura S, Shouzu A, Omoto S, Inami N, Ueba T, Urase F, Maeda Y: Effects of eicosapentaenoic acid on endothelial cell-derived microparticles, angiopoietins and adiponectin in patients with type 2 diabetes. J Atheroscler Thromb 2009;16:83-90.

55 Nomura S, Kanazawa S, Fukuhara S: Effects of eicosapentaenoic acid on platelet activation markers and cell adhesion molecules in hyperlipidemic patients with Type 2 diabetes mellitus. J Diabetes Complications 2003;17:153-159.

56 Nomura S, Inami N, Shouzu A, Omoto S, Kimura Y, Takahashi N, Tanaka A, Urase F, Maeda Y, Ohtani H, Iwasaka T: The effects of pitavastatin, eicosapentaenoic acid and combined therapy on platelet-derived microparticles and adiponectin in hyperlipidemic, diabetic patients. Platelets 2009;20:16-22.

57 Nomura S, Inami N, Kimura Y, Omoto S, Shouzu A, Nishikawa M, Iwasaka T: Effect of nifedipine on adiponectin in hypertensive patients with type 2 diabetes mellitus. J Hum Hypertens 2007;21:38-44.

58 Chen Y, Feng B, Li X, Ni Y, Luo Y: Plasma Endothelial Microparticles and Their Correlation With the Presence of Hypertension and Arterial Stiffness in Patients With Type 2 Diabetes. J Clin Hypertens (Greenwich) 2012;14:455-460.

59 Inami N, Nomura S, Shouzu A, Omoto S, Kimura Y, Takahashi N, Tanaka A, Nanba M, Shouda Y, Iwasaka T: Effects of pitavastatin on adiponectin in patients with hyperlipidemia. Pathophysiol Haemost Thromb 2007;36:1-8.

60 Ouvina SM, La Greca RD, Zanaro NL, Palmer L, Sassetti B: Endothelial dysfunction, nitric oxide and platelet activation in hypertensive and diabetic type II patients. Thromb Res 2001;102:107-114.

61 Aurelian SM, Cheta DM, Onicescu D: Microvesicles - potential biomarkers for the interrelations atherosclerosis/type 2 diabetes mellitus. Rom J Morphol Embryol 2014;55:1035-1039.

62 Puddu P, Puddu GM, Cravero E, Muscari S, Muscari A: The involvement of circulating microparticles in inflammation, coagulation and cardiovascular diseases. Can J Cardiol 2010;26:140-145.

63 Horstman LL, Ahn YS: Platelet microparticles: a wide-angle perspective. Crit Rev Oncol Hematol 1999;30:111-142.

64 Ferroni P, Basili S, Falco A, Davi G: Platelet activation in type 2 diabetes mellitus. J Thromb Haemost 2004;2:1282-1291.

65 Aoki I, Shimoyama K, Aoki N, Homori M, Yanagisawa A, Nakahara K, Kawai Y, Kitamura SI, Ishikawa K: Platelet-dependent thrombin generation in patients with diabetes mellitus: effects of glycemic control on coagulability in diabetes. J Am Coll Cardiol 1996;27:560-566.

66 Berezin AE, Kremzer AA, Berezina TA, Martovitskaya YV: The pattern of circulating microparticles in patients with diabetes mellitus with asymptomatic atherosclerosis. Acta Clin Belg 2016;71:38-45.

67 Jimenez JJ, Jy W, Mauro LM, Soderland C, Horstman LL, Ahn YS: Endothelial cells release phenotypically and quantitatively distinct microparticles in activation and apoptosis. Thromb Res 2003;109:175-180.

68 Tsai WH, Shih CH, Feng SY, Li IT, Chang SC, Lin YC, Hsu HC: CX3CL1(+) microparticles mediate the chemoattraction of alveolar macrophages toward apoptotic acute promyelocytic leukemic cells. Cell Physiol Biochem 2014;33:594-604.

69 Dignat-George F, Boulanger CM: The many faces of endothelial microparticles. Arterioscler Thromb Vasc Biol 2011;31:27-33. 